Psychology of Language and Communication 2016, Vol. 20, No. 3

DE DE GRUYTER

DOI: $10.1515 /$ plc-2016-0014

ANNA MILANOWICZ, PIOTR KAŁOWSKI

University of Warsaw

\title{
ZING ZING BANG BANG: HOW DO YOU KNOW WHAT SHE REALLY MEANT. GENDER BIAS IN RESPONSE TO IRONY: THE ROLE OF WHO IS SPEAKING TO WHOM
}

\begin{abstract}
Literature points towards the role of context in irony interpretation and the existence of gender differences in language use. We decided to examine the influence of interlocutors' gender stereotypes on interpreting and reacting to ironic criticism in conversation. To this end, we designed two experiments gathering participants' responses to the same ironic utterances voiced both by women and by men in control and gender stereotype activation conditions. Results of the first experiment showed that women tended to use irony significantly more often when responding to a man than to another woman. The second, ongoing experiment will additionally examine participants' response times and total time of utterance in respect to their addressee's gender. The results are discussed with regard to the social comparison theory (Turner, Hogg, Oakes, Reicher, \& Wetherell, 1987) and the linguistic intergroup bias theory (Wigboldus \& Douglas, 2007).

Key words: irony, figurative language, gender, gender stereotypes, social cognition
\end{abstract}

\section{Introduction}

Most of us probably abide by the credo of "I am only responsible for what I say, not for what you understand." But why is it that our word processing software seems to run differently depending on the hardware we use? What makes us cut, copy, and paste any given information in this way or another? Intrigued by both language and cognition, we decided to approach the topic of irony as a quite challenging situation of conflicting data input processing and look at it through the lens of gender bias in communication. We did not, however, aim to

Address for correspondence: Anna Milanowicz, Faculty of Psychology, University of Warsaw, Stawki 5/7, 00-183 Warsaw, Poland. E-mail: ania.milanowicz@gmail.com 
see how gender dictates communication style - a topic which has already been broadly described. Rather, our aim was to see how the gender of the person we are interacting with twists and refocuses our own way of thinking.

In his 2002 article, "Humor and Irony in Interaction: From Mode Adoption to Failure of Detection" Salvatore Attardo writes that "the study of humor, irony, and other playful forms is plagued by definitional problems" (Attardo, 2002, p. 166). Considering the complex character of verbal interaction, Attardo's claim is hardly an overstatement. Researchers of irony use and/or comprehension face an array of interfering variables that can perhaps be controlled for, but never fully eliminated. Some of those variables stem from the necessity of creating appropriate experimental conditions (e.g., choosing easily understandable ironic utterances for stimuli). Others (e.g., the intergroup relation between the speaker and the recipient of an ironic utterance) are related to the context of the verbal interaction itself, which is equally important to irony use and comprehension (Attardo, 2002). Both of these kinds of variables can influence an experiment's ecological validity, and thus the obtained results. Therefore, to make accurate empirical measurements of the phenomenon of verbal irony, it is important to consider in detail both the experimental stimuli, that is, ironic utterances, as well as the context in which they are presented to the participants in the design stage of an experiment (Gibbs, 2000; Kotthoff, 2003).

However, this methodological complexity should not be surprising, as irony itself is of contradictory nature. Besides granting the speaker a way of "taking back" their words (Attardo, 2002; Bromberek-Dyzman, 2012), "saying what you do not mean" serves a variety of conversational goals. On the one hand, it can add humor to one's utterances (Colston \& O'Brien, 2000) by providing the recipient with an opportunity to recognize an unexpected discrepancy between the speaker's utterance and the actual beliefs they hold (Longman \& Graesser, 1988). Its inherent humor can thus help mitigate the criticism also expressed through irony (Dews, Kaplan, \& Winner, 1995). Ironic "praise by blame" can similarly soften the impression of flattering the recipient which literal praise could give (Dews et al. 1995). However, ironic criticism can also be intensified by a characteristic pronounced and scornful voice, implying a lack of emotional arousal on the part of the speaker (Anolli, Ciceri, \& Infantino, 2002). The fact that, being a figurative utterance, irony requires more cognitive effort from the speaker additionally underscores the weight of criticism it contains (Jorgensen, 1996).

Irony is thus a social tool, and gains its meaning in the wider context of social interaction. We are social, and so we are culturally accustomed to think and act in certain ways. We are all molded to fit the frames of our times and social expectations. We are trained to take mental shortcuts in our everyday life and we are taught to identify ourselves as being similar to or different form others. Already at very early ages, girls begin defining their femininity in relation to boys (Freud, 1927; Mead, 1935/2001; Weitzman, 1979). Similarly, boys are taunted 
for acting like a girl, or crying like a girl, implying that being a girl is worse than being a boy. Because of the pervasiveness of gender stereotypes in social interactions and because of their function as cognitive shortcuts, we decided to incorporate them into our experiment designs and see how irony functions within the contexts of inter- and intragender interactions.

As stated above, the choice of goals towards which to employ irony relies on the interpersonal context of verbal interaction (Gibbs, 2000). One important factor influencing that choice of goals is the speakers' gender, as it is tied to a number of differences in language use and understanding. To avoid methodological inaccuracies, gender is often conceptualized in terms of warmth and competence (Abele, 2003; Fiske, Cuddy, \& Glick, 2007). Warmth and competence are accurate and economical descriptive dimensions: they "account for $82 \%$ of the variance in perceptions of everyday social behaviors" (Fiske et al., 2007, p. 77). Warmth corresponds roughly to stereotypical conceptions of femininity (Abele, 2003), including "friendliness, helpfulness, sincerity, trustworthiness and morality" (Fiske et al., 2007, p. 77). Competence, on the other hand, closely resembles stereotypical masculinity (Abele, 2003), being characterized by skill, efficacy, emphasis on individualism, and egoism (Fiske et al., 2007; Guimond, Chatard, Martinot, Crisp, \& Redersdorff, 2006).

Differences in warmth and competence translate to differences in language use and comprehension between men and women. Topics related to emotions and interpersonal relationships appear more often in talk among women than among men, whereas men provide information and advice and talk about task-related topics more often than women (Wojciszke, 2010). Colston and Lee (2004) report that "fictional speakers of unknown gender who use verbal irony to comment about relatively negative situations are thought to most likely be male" and that "males report a greater likelihood of using verbal irony in negative situations" (p. 301). Moreover, when making comments without obvious intentions, males tend to be perceived as more sarcastic than females. For comments with obvious intentions, this trend is reversed (Katz, Piasecka, \& Toplak, 2001). Women also show a greater tendency to interpret utterances as figurative than do men (Holtgraves, 1991).

Research by Milanowicz (2013) showed that males and females differ in emotional attitude towards irony and hence in the discourse goals they attempt to meet by using it: Males report using irony to amuse their listeners and to distance themselves from difficult situations, and they perceive irony as facilitating bonding responses, while for females, irony is more negative and reinforces disapproval and criticism which could otherwise be expressed in a direct literal comment. Males also described themselves as ironic more often than women did (2013). Colston and Lee (2004) posit that men tend to use irony more often than women because their pragmatic goals in conversations more often include expressing a critical lack of approval. Alternatively, men could be more ironic 
because they show a greater propensity towards risk-taking, and irony usage involves a certain risk of being misunderstood.

With reference to the politeness theory (Brown \& Levinson, 1987; Lakoff, 1973), the impoliteness strategy (Culpeper, 1996), and research on stereotypes by Wojciszke (2010), we wanted to see whether, for women, irony becomes a way of expressing repressed aggression. According to stereotypical conceptions of femininity, there is no social approval for women to show anger, and for that reason irony can be a form of expressing frustration verbally, which allows women to adapt to expectations while avoiding social disapproval through its ambiguity and indirectness.

As was described above, the dimensions of warmth and competence parallel conceptions of femininity and masculinity. However, self-reports by both genders in terms of these two dimensions differ only slightly, with both males and females ascribing more warmth than competence to themselves (Wojciszke, 2010). Expected differences in warmth and competence self-reports corresponding to gender stereotypes occur only in the context of intergroup comparison (Guimond et al., 2006). Stereotype use in an intergroup context is facilitated by their cognitive value: They predict others' behavior and suggest how one should behave in turn (Biernat \& Manis, 2007; Moskowitz, 2005). Stereotyping extends as well to the situations themselves: "Depending on the primed context, people construe some ambiguous social behaviors in either warmth or competence terms (e.g., tutoring a friend, avoiding a car accident, failing to cheer up a sibling and leaving a meeting)" (Fiske et al., 2007: p. 79). Stereotyping is further complemented by self-stereotyping, with an individual emphasizing their differences from the group they belong to in the context of intergroup comparison, and in the context of intragroup comparison - their differences. This phenomenon, described by the so-called self-categorization theory, stems from the attempt of balancing one's identity between individualism and a sense of belonging, without risking neither alienation nor loss of identity (Guimond et al., 2006; Turner, Hogg, Oakes, Reicher, \& Wetherell, 1987).

If we accept irony as the manifestation of abstract language, and saying something directly as the manifestation of literal language, we can assume that when addressing one's own group (the ingroup, i.e., same-sex interlocutor), irony will be used rather in a positive context (e.g., to praise) while literal language will be employed in a negative context. The opposite will be true towards anyone viewed as outside of the ingroup (in the outgroup, i.e., an opposite sex interlocutor), and use of irony should then be preferred in negative contexts (e.g., to criticize). Thus, women and men will understand irony communicated by a same-sex person differently than if communicated by an opposite-sex person. This assumption is supported by the linguistic intergroup bias (Wigboldus \& Douglas, 2007), which causes desirable behavior of in-group members to be interpreted on an abstract cognitive level, while negative behavior is interpreted on a more concrete one. 
This phenomenon is reversed when interpreting outgroup member behavior, which helps maintain a more positive image of one's own group, and a negative image of the out-group. In light of these facts, the current study focused on the effects of gender stereotype activation in the process of verbal communication.

\section{Experiment 1}

The aim of the first experiment (Milanowicz, 2016) was to see what relationship exists, if any exists at all, between gender and response to irony. The Irony Processing Task (IPT) was developed in order to measure the role of who is speaking to whom and to see how a personal factor like gender can channel the way ironic meaning and ironic response are generated in everyday situations. It was hypothesized that males and females would respond to ironic criticism differently depending on who it comes from, that is, women would respond differently to a man than to another woman, and men would respond differently to a woman than to another man. It was also believed that an additional application of experimental gender stereotype activation would reinforce gender differences in attributing different meanings, congruent with these stereotypes, to ironic utterances. A good deal of work has shown that a person's mood can influence the perception and evaluation processes (Isen \& Shalker, 1982; Teasdale, \& Fogarty, 1979). It was hypothesized that a presentation of a list of 16 positive personality traits for the participant to choose from when describing oneself as being more intelligent, caring, reliable, and so on, as compared with "most women/men I know" would reinforce the situation of social comparison and induce positive mood towards one's own group members and a sense of superiority towards outgroup members. This would impact the style and content of responses to ironic criticism coming from both the in- and outgroup members. It was also hypothesized that a presentation of 16 negative personality traits to choose from when describing oneself as being "more like" as compared with "most women/ men I know", would induce a lower mood and a sense of inferiority towards the participant's outgroup. It was believed it would make participants act more aggressively or more directly and place more blame on themselves when confronted with an ironic utterance coming from an outgroup member.

\section{Method}

\section{Participants}

Irony comprehension and responses were measured on a female-only sample. A total of 127 subjects (female students from the University of Warsaw) took part in the study (age range 18-43 years, $M_{\text {age }}=19,98 ; S D=1,44$ ). The participants verbally provided their informed consent to taking part in the study. The participants were granted full anonymity of the data gathered for the analyses and were 
informed that only group results will be described. We looked at three data sets, obtained from a control group $(n=56)$, a group with positive pre-task priming $(n=35)$, and a group with negative pre-task priming $(n=36)$.

\section{Measures}

A very distinct quality of irony is its openness to more than one interpretation. Taking Kotthoff's (2003) assumption that, from the format of the responses one may attempt to enter the format of irony processing as a starting point, the IPT was administered to the research participants. The questionnaire was developed by Milanowicz (2016) to measure the production and comprehension of irony in adults. As there is a general belief that females tend to perform better on tasks requiring decoding of nonverbal information (Collignon, Girard, Gosselin, Saint-Amour, Lepore, \& Lassonde, 2010; Hall, 1984), a pen-and-paper questionnaire was administered to eliminate any non-verbal or auditive decoding cues. Any indicators of a prosodic or kinetic character, as well as facial cues, were neither considered nor present. The IPT presents three different tasks involving 11 diversified situations and ironic comments. All of the tasks measure not only comprehension but most importantly reaction and responses to irony. In this article we focus on the results of task 1, which describes contextual introduction of two criticism-worthy situations and ironic comments of "blame by praise" when the comment itself is wrapped up in an apparent compliment. One situation presents a comment made by a female friend and another, analogous, situation presents a comment made by a male friend. Participants were the direct target of these comments. The imagined scenarios were designed to have a close relationship to real life situations where participants could easily draw on their experience and access gender stereotypes in formulating their response.

\section{Procedure}

Participants completed a set of questionnaires during a course meeting and were instructed to respond fast and spontaneously. Irony as an unexpected and ambiguous stimulus can evoke a state of "flight of fight" alertness. It was assumed that, in order to arrive at a response to such a stimulus, subjects would instinctively refer to their cognitive schemas, personal knowledge and interactional experience while confronting it.

In experimental groups, lists of adjectives were administered first, followed by the IPT. Negative trait adjectives administered to female participants were assumed to undermine self-esteem and reinforce a negative self-image and image of females in general. Positive trait adjectives, however, were believed to have a morale- and self-esteem boosting effect reinforcing a positive self-image, as well as a positive image of females (in-group members) in general (in-group members). To assure study validity, 3 sets of tests were distributed randomly. The order of presented tasks was kept the same for all tested individuals. 


\section{Data Analysis}

The participants' responses to ironic blame by praise were classified, on the basis of ratings by three independent judges, into five categories (Interrater reliability between three raters was measured with Kendall's $W$ test; $W(34)=0.92$ and $W(34)=0.93$, respectively, for Female-Female and Female-Male blame by praise configuration with positive priming beforehand; $W(35)=0.94$ and $W(35)=0.99$, respectively, for Female-Female and Female-Male blame by praise configuration with negative priming beforehand):

1. Irony acknowledgement and ironic response (e.g., "It's very funny" when, as a matter of fact, it is not).

2. Irony acknowledgement but continuing on a serious note and staying out of the ironic tune, (e.g., "Screw you. Try to come up with a better idea.")

3. Irony acknowledgement and responding with a mixed message of both ironic and literal mode (e.g., "Thanks! Try to do it yourself!").

4. Lack of irony acknowledgement and responding in a confused manner (e.g., "What are you talking about? It wasn't like that at all.")

5. Unclassifiable, where the response is not ironic but does not provide enough information as to irony detection (e.g., "Thank you for the comment.")

These five categories were merged into two main groups of (a) non-ironic and (b) ironic responses. Categories 2, 4, and 5 were merged into non-ironic response group of reactions, while categories 1 and 3 were grouped into ironic reactions.

As responses on two measures were used (coded as either ironic or not, i.e. indicating a comprehension of mockery and ironic response to it or lack of thereof), a contingency table analysis was applied and the McNemar's chi-square for within-subjects test was used.

\section{Results}

Analyses of the IPT data confirmed the existence of a gender effect. Collected data shows that the same stimulus can moderate different verbal behaviors that range from reacting to what is said to reacting to what is implicated. But, unquestionably, a new thing here is that these responses to inconsistent verbal stimuli are quite consistent when it comes to gender. The analysis shows that there is a relationship between the use of non-literal language and gender. Not only who is talking but also who is listening seems to add a whole new dimension of meaning to ironic comments.

A significant association exists between gender and response to irony, in other words, between what is said and who it is said to. As anticipated, McNemar's chi-square showed significant ironic response favorability towards men in all 
conditions $(p<0.001)$.Women used significantly more ironic responses towards men than other women in control group $(\chi 2=21.33, p=0.000<0.001)$. The same effects of majority of ironic responses given to men and more literal comments expressed towards women was observed in the group with positive priming $(\chi 2=10.71, p=0,001<0.01)$. Also, ironic performance was significantly higher in female-male interactions as compared to female-female responses in the negative priming condition, $\chi 2=8.07, p=0,007<0.01$.

In the control group (see Figure 1), $73 \%$ of the women were more likely to use irony towards men than towards other women (29\%).

Figure 1. Female response to irony

\section{Female Response to Irony}

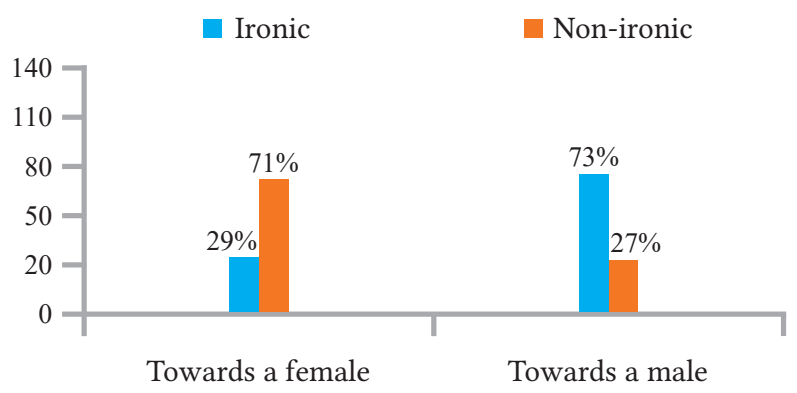

Also, in the positive priming condition (see Figure 2), more women acted in an ironic fashion towards opposite-sex interaction participants (71\%) than same-sex interaction participants $(26 \%)$.

Figure 2. Female response to irony in positive pre-task priming

Female Response to Irony in Positive pre-task Priming

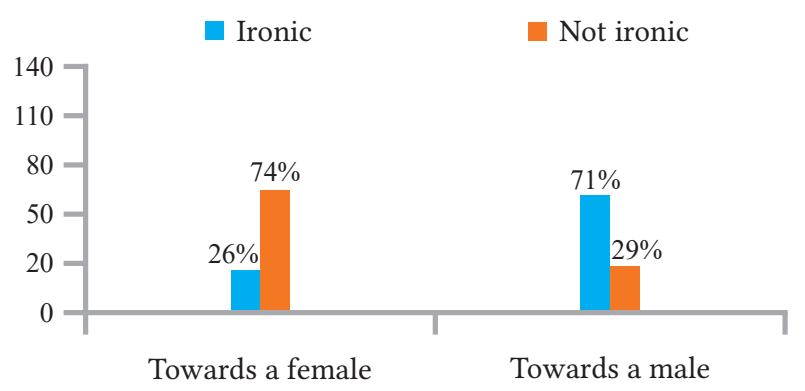


Finally, the negative priming group (see Figure 3) shows similar results, with $78 \%$ women using irony in their response to ironic comments made by a man compared to only $20 \%$ ironic comments reciprocated with a woman.

Figure 3. Female response to irony in negative pre-task priming

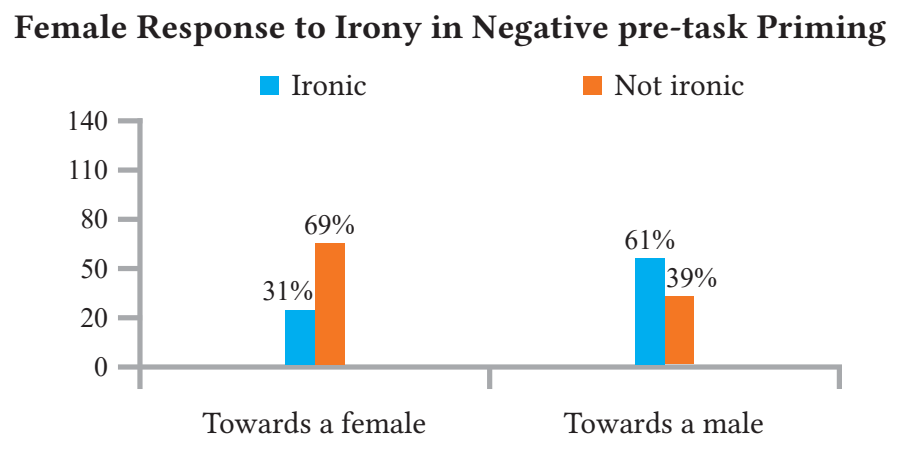

The results show that women respond differently to ironic comments made by another woman (in-group member) than they do to ironic comments made by a man (out-group member).

By showing how different meaning can be assigned to the same verbal stimuli in the same context, where only the gender of the speaker who becomes the listener changes, we are able to see that this one variable has a notable influence on the participants' linguistic choices.

\section{Discussion}

In this experiment, we investigated gender effects on responses to irony within the Irony Processing Task (IPT), designed to simulate detection and production of non-literal verbal comments. It was confirmed that females were more ironic towards males than towards other females in all test conditions. Interestingly, as only female participants were tested for now, the experiment clearly shows not only the role of who is speaking to whom but also the importance of who is listening to whom. Listeners have agency too, choosing the interpretation of what the speaker says and assigning their own meaning to what is said. The speaker chooses the resources they wish to employ to speak their mind, but the listener is not required to choose exactly the same meaning as intended by the speaker.

The results are consistent with and support the phenomenon of the linguistic intergroup bias (Wigboldus \& Douglas, 2007). The experiment shows that towards one's own group, that is, towards other women, abstract language was not used 
much in the context of ironic criticism. Literal language was significantly more present in responses to irony employed in a negative situation and expressed by an in-group member. Yet, abstract language was kept in responses to ironic criticism expressed towards out-group members, where literal comments were significantly less frequent.

We did not observe a significant impact of positive or negative gender stereotype activation through experimental methods. This can actually mean that our perception of sameness and reaction to otherness goes beyond the whim of the moment. The sense of self is grounded yet flexible and the eternal question of "Who am I?" could go far and deep into "Who am I when I talk to you."

\section{Experiment 2}

Experiment 1 has shown that the addressee's gender in relation to the speaker is an important variable determining the frequency of ironic responses. As the data came from female speakers only, the results showed the role of "to whom" in "who is speaking to whom." Data from male participants will be collected in the future. Experiment 2 aims to corroborate the results from Experiment 1in a more ecologically valid experimental situation by including ironic stimuli in the form of videos of a male or female actor addressing the participant, filmed from a first-person perspective, with the assumption that a visual presentation of an outgroup member would facilitate the processes of stereotyping and self-stereotyping (Kałowski, in preparation) ${ }^{1}$. Research shows that videos are effective at emotion elicitation (Gross \& Levenson, 1995; Soleymani, Pantic, \& Pun, 2012; Wu et al., 2010). Todorov, Said, Engell, and Oosterhof (2008) have also shown that instinctive trait inferences from faces can be mapped on a two-dimensional space of warmth and competence.

Another argument for presenting ironic utterances in the form of videos is that prosodic markers of irony have been tied to particular relational contexts (Anolli et al., 2002): In a context of cooperation, "kind irony" can be expressed through a "rather high and changeable pitch, a strong energy, and a slow rhythm" (p. 273) or through a low, monotone pitch which caricatures a tender, concerned voice. In a conflict context, sarcastic irony is similarly characterized by "a very high and changeable pitch, a strong energy, and a slow rate of articulation" (p. 273). It can alternatively be expressed through a slow and monotonous scornful voice. However, some researchers state that an ironic tone of voice is not necessary for irony comprehension, and it can inhibit it in some cases (Cutler, 1974; Gibbs \& O’Brien, 1991; Kreuz \& Roberts, 1995). Kreuz and Roberts (1995) suggest that

\footnotetext{
${ }^{1}$ Experiment 2 is being conducted as part of a master's thesis. It is a modification of a previous seminar thesis (Kałowski, 2015) which involved a pen-and-paper questionnaire gathering responses to ironic utterances voiced both by men and women. Some of the stimuli used in that questionnaire appear in video form in Experiment 2.
} 
prosodic markers of irony play a role in irony comprehension when the interlocutors share only a small amount of information together. However, as prosody is an inseparable part of everyday communication, in order to increase ecological validity it was included in Experiment 2 through the usage of videos.

Additionally, instead of collecting the participants' responses on paper, Experiment 2 will involve recording the responses being spoken out loud. Aside from rating the responses as ironic or nonironic, data gathered in such a form will allow for examining whether gender differences between interlocutors in a situation of irony use will manifest in such factors as response time (RT), the total length of response, or the intensity of prosodic marking. Emphasis will thus be placed on the "who is speaking" part in "the role of who is speaking to whom."

\section{Method}

\section{Participants}

At the time of writing this article, the second experiment is still being conducted. As such, the sample of participants does not yet reach the anticipated final size of 60 people, both female and male: Only 23 participants (16 females and seven males, $\left.M_{\text {age }}=21.61\right)$ were recruited so far. Likewise, statistical analyses of the gathered data are of a preliminary character only.

\section{Measures}

A set of twenty videos was recorded, employing, with their full consent, members of the Academic Theatre Company of the Institute of English Studies at the University of Warsaw. The set consisted of ten scenarios, each in two variants: one ending in the actor producing an ironic utterance, the other with the actor producing an emotionally neutral utterance. The scenarios depicted everyday scenes, such as improperly parking a car, and were introduced by a narrated voice-over in second-person form (i.e., "You are doing..."). This decision was motivated by the fact that irony has no distinct facial cues which would directly signal irony usage. Instead, it shares them with other figurative modes of language (Bromberek-Dyzman, 2011). Proper interpretation of such elements of facial expression as (a) raising or lowering of eyebrows, (b) squinting, (c) smiling, or (d) keeping a neutral expression as ironic also requires an appropriate degree of shared information between interlocutors (Barbe, 1995), and an overemphasis on facial expression can "be harmful for the transparency of relations between speaker and recipient" (Bromberek-Dyzman, 2011, p. 8). To ensure that participants will be provided with enough information about the context in which a given ironic utterance is produced so that the actors' facial expressions and 
tones of voice facilitate, rather than inhibit, irony comprehension, each video contains a short introduction by a narrator, explaining what prompted the actor to make an ironic comment (i.e., "You parked the car wrong. Your friend turns to you and says...”).

The narrative descriptions ended with a sound sample related to the scenario (e.g., the sound of car doors closing), after which the actor, addressing the camera directly, delivered their utterance. Each scenario, in both the ironic and the non-ironic variant, was recorded in a version with a male or a female narrator, as well as a male or a female actor, producing the following versions of each of the ironic and non-ironic scenarios: (a) male narrator/male actor, (b) male narrator/ female actor, (c) female narrator/male actor, and (d) female narrator/female actor.

Such a video pool allowed for creating situations where the participants in the experiment, regardless of their gender, reacted to both ironic and non-ironic utterances addressed to them both by males and by females, all within one trial. Male and female narrators have also been included, in case they were revealed to have had an effect on the participants' reactions.

To create conditions of exacerbated interpersonal context in line with the self-categorizaton theory, a stereotype-activating task, adapted from Wojciszke and Szlendak (2010) is planned to be administered to some of the experiment's participants, creating a group for comparison. The task involves being presented with a list of forty stereotypical male and forty stereotypical female professions, and being asked to count the number of syllables in each word.

\section{Procedure}

All 23 participants were assigned to the group without additional gender stereotype priming. The experiment was carried out individually. After expressing verbal consent, the participants were seated in a room in front of a laptop computer that was used to screen the stimulus videos and introduced to the procedure without the experimenter disclosing the research hypothesis. The videos were screened for the participants using a computer program designed in Python specifically for the purpose of this experiment.

The participants were first led through a practice task, identical to all the proper experiment trials. Each trial consisted of the participant viewing a single video, selected randomly from the video pool according to one of the four series mentioned above assigned randomly to each participant. Then, a message informing the participant to give their verbal response to the scene was displayed on the screen, alongside with a $3 \mathrm{~s}$ countdown. After giving their response, the participants proceeded to the next stage of the experiment manually, where they rated the video's humor and criticism on a scale from 0 to 100. Each participant went through eight such trials. Additionally, the computer program used to carry out the experiment measured the length of the participants' utterances. The order of the stimuli varied between series, so that, for example, a participant 
assigned to one series was shown eight videos with a male narrator (in which four featured a male actor and four a female one), and in another, eight videos with a male actor (four of them with a male, and four with a female narrator). In any case, however, the content of the scenarios themselves did not repeat, so that the participants did not, for example, watch a scene where the actor jokes about their parking twice, once with a female, and once with a male actor.

\section{General Discussion}

Experiment 1 has presented evidence confirming the existence of the linguistic intergroup bias (Wigboldus \& Douglas, 2007): Females used irony significantly more often towards men, that is, outgroup members, than towards women, their ingroup members. Thus, gender was proven to be an important variable stimulus influencing irony usage,. The results support the notion that gender differences in self-construal are the product of social comparison processes (Guimond et al., 2006; Milanowicz \& Bokus, 2013), and that self-representation and representation of others on the verbal communication level are the product of adaptation to inner and outspoken social expectations, where irony challenges the situation on a symbolic level, and becomes a silent "no" in response to reality. It can be that women keep the playful tone in conversation with men but it can also be that they give men a taste of their own medicine. Irony is not always humorous, and in line with previous research by Milanowicz (2013), irony can be seen also here as a more heavily-loaded vehicle for criticism, mockery and frustration, while use of direct and literal response to ironic criticism can be seen as a way to play down the harmful effect of disapproval. In order for the ironic performance to be successful, access and adoption of the same code and style should convey congruent meanings, which might not always be the case in human communication. Additionally, in the social world of interaction, there are consequences of intelligibility and miscommunication. These results also corroborate the results of the study by Milanowicz and Bokus (2013), which revealed that a simple change of gender setting, that is, of who is speaking to whom, brings about different results in moral judgments The same phenomenon of gender acting as a catalyst for certain social behaviors can also turn out to be true for ironicity. The role of who is speaking to whom will be examined more closely still as the experiments outlined in this article progress: By including data from male participants responding to both female and male blame by praise, the "to whom" factor will be given closer consideration in Experiment 1. Experiment 2 will seek to compound that analysis by focusing on the role of "who is speaking" through gathering participants' RTs and time needed to produce a complete response and seeing whether these variables will differ when addressing ingroup and outgroup interlocutors. 


\section{Acknowledgments}

The authors would like to thank all those who contributed to the completion of this article. We express our thanks to Professor Barbara Bokus from of the University of Warsaw for allowing us to carry out the experiment in her classes. Finally, our deep sense of gratitude goes to the students for their agreement to participate in the study.

\section{References}

Abele, A.E. (2003). The dynamics of masculine-agentic and feminine-communal traits: findings from a prospective study. Journal of Personality and Social Psychology, 85 (4), 768-776.

Anolli, L., Ciceri, R., \& Infantino, M.G. (2002). From" blame by praise” to" praise by blame": Analysis of vocal patterns in ironic communication. International fournal of Psychology, 37 (5), 266-276.

Attardo, S. (2002). Humor and irony in interaction: From mode adoption to failure of detection. In L. Anolli, R. Ciceri, \& G. Riva (Eds.), Say not to Say: New Perspectives on Miscommunication (pp. 159-179). Amsterdam: IOS Press.

Biernat, M. \& Manis, M. (2007). Stereotypes and Shifting Standards: Assimilation and Contrast in Social Judgment. New York, NY: Psychology Press.

Bromberek-Dyzman, K. (2011). Język emocji a język ironii w pragmatyce eksperymentalnej. Studia z Kognitywistyki i Filozofii Umystu, 5(1), 5-38.

Bromberek-Dyzman, K. (2012). Affective twist in irony processing. Humana. Mente Journal of Philosophical Studies, 23, 83-111.

Brown, P. \& Levinson, S.C. (1987). Politeness: Some Universals in Language Usage (Vol. 4). Cambridge, UK: Cambridge University Press.

Collignon, O., Girard, S., Gosselin, F., Saint-Amour, D., Lepore, F., \& Lassonde, M. (2010). Women process multisensory emotion expressions more efficiently than men. Neuropsychologia, 48 (1), 220-225.

Colston, H.L. \& Lee, S.Y. (2004). Gender differences in verbal irony use. Metaphor and Symbol, 19 (4), 289-306.

Colston, H.L. \& O'Brien, J.E. (2000). Contrast of kind versus contrast of magnitude: The pragmatic accomplishments of irony and hyperbole. Discourse Processes, 30 (2), 179-199.

Culpeper, J. (1996). Towards an anatomy of impoliteness. fournal of Pragmatics, 25 (3), 349-367.

Cutler, A. (1974). On saying what you mean without meaning what you say. In M.W. Fox, R.A. Bruck, \& A. La Galy (Eds.), Papers from the Tenth Regional Meeting Chicago Linguistic Society (pp. 17-127). Chicago: CLS.

Dews, S., Kaplan, J., \& Winner, E. (1995). Why not say it directly? The social functions of irony. Discourse Processes, 19 (3), 347-367. 
Fiske, S.T., Cuddy, A.J., \& Glick, P. (2007). Universal dimensions of social cognition: Warmth and competence. Trends in Cognitive Sciences, 11 (2), 77-83.

Freud, S. (1927). The Future of an Illusion. London, UK: Hogarth Press.

Gibbs, R.W. (2000). Irony in talk among friends. Metaphor and Symbol, $15(1-2), 5-27$.

Gibbs, R.W. \& O’Brien, J. (1991). Psychological aspects of irony understanding. fournal of Pragmatics, 16 (6), 523-530.

Gross, J.J., \& Levenson, R.W. (1995). Emotion elicitation using films. Cognition \& Emotion, 9 (1), 87-108.

Guimond, S., Chatard, A., Martinot, D., Crisp, R.J., \& Redersdorff, S. (2006). Social comparison, self-stereotyping, and gender differences in self-construals. Journal of Personality and Social Psychology, 90 (2), 221-242.

Hall, J.A. (1984). Nonverbal Sex Differences: Communication Accuracy and Expressive Style. Baltimore, MD: The Johns Hopkins University Press.

Holtgraves, T. (1991). Interpreting questions and replies: Effects of face-threat, question form, and gender. Social Psychology Quarterly, 54 (1), 15-24.

Isen, A.M. \& Shalker, T.E. (1982). The influence of mood state on evaluation of positive, neutral, and negative stimuli: When you "accentuate the positive," do you "eliminate the negative"? Social Psychology Quarterly, 4, 58-63.

Jorgensen, J. (1996). The functions of sarcastic irony in speech. Fournal of Pragmatics, $26(5), 613-634$.

Kałowski, P. (2015). Gender of the speaker and the addressee of an ironic utterance and irony comprehension. (Unpublished seminar thesis). University of Warsaw.

Kałowski, P. (2016). The effect of gender on irony understanding. Master's thesis in preparation. University of Warsaw.

Katz, A., Piasecka, I., \& Toplak, M. (November 2001). Comprehending the sarcastic comments of males and females. Paper presented at the 42nd Annual Meeting of the Psychonomic Society, Orlando, FL.

Kotthoff, H. (2003). Responding to irony in different contexts: On cognition in conversation. Journal of Pragmatics, 35 (9), 1387-1411.

Kreuz, R.J. \& Roberts, R.M. (1995). Two cues for verbal irony: Hyperbole and the ironic tone of voice. Metaphor and Symbol, 10 (1), 21-31.

Lakoff, R.T. (1973). The logic of politeness; or minding your p's and q's. In C. Corum, T.C. Smith Stark, \& A. Weiser (Eds.), Papers from the 9th Regional Meeting of the Chicago Linguistic Society (pp. 292-305). Chicago, IL: The University of Chicago Press.

Longman, D.L. \& Graesser, A.C. (1988). Wit and humor in discourse processing. Discourse Processes, 11 (1), 35-60.

Mead, M. (2001). Sex and Temperament: In Three Primitive Societies. New York, NY: Harper Perennial. (Original work published 1935)

Milanowicz, A. (2016). Irony processing task (Unpublished questionnaire from doctoral thesis). University of Warsaw. 
Milanowicz, A. (2013). Irony as a means of perception through communication channels. Emotions, attitude and IQ related to irony across gender. Psychology of Language and Communication, 17 (2), 115-132.

Milanowicz, A. \& Bokus, B. (2013). Gender and moral judgments: The role of who is speaking to whom. Journal of Gender Studies, 22 (4), 423-443.

Moskowitz, G.B. (2005). Social Cognition: Understanding Self and Others. New York, NY: Guilford Press.

Soleymani, M., Pantic, M., \& Pun, T. (2012). Multimodal emotion recognition in response to videos. IEEE Transactions on Affective Computing, 3(2), 211-223.

Teasdale, J.D. \& Fogarty, S.J. (1979). Differential effects of induced mood on retrieval of pleasant and unpleasant events from episodic memory. Fournal of Abnormal Psychology, 88 (3), 248-257.

Todorov, A., Said, C.P., Engell, A.D., \& Oosterhof, N.N. (2008). Understanding evaluation of faces on social dimensions. Trends in Cognitive Sciences, 12 (12), 455-460.

Turner, J.C., Hogg, M.A., Oakes, P.J., Reicher, S.D., Wetherell, M.S. (1987). Rediscovering the Social Group: A Self-Categorization Theory. Oxford: Blackwell.

Weitzman, L.J. (1979). Sex Role Socialization. Palo Alto, CA: Mayfield

Wigboldus, D. \& Douglas, K.M. (2007). Language, stereotypes, and intergroup relations. In K. Fiedler (Ed.), Social Communication (pp. 79-106). New York, NY: Psychology Press.

Wojciszke, B. (2010). Sprawczość i wspólnotowość: podstawowe wymiary spostrzegania społecznego. Gdańsk: Gdańskie Wydawnictwo Psychologiczne.

Wojciszke, B., Szlendak, M.A. (2010). Skale do pomiaru orientacji sprawczej i wspólnotowej. Psychologia Społeczna, 5 (1), 57-70.

Wu, D., Courtney, C.G., Lance, B.J., Narayanan, S.S., Dawson, M.E., Oie, K.S., \& Parsons, T.D. (2010). Optimal arousal identification and classification for affective computing using physiological signals: virtual reality Stroop task. IEEE Transactions on Affective Computing, 1 (2), 109-118. 